\title{
FíSTULA ORONASAL BILATERAL EM CÃO TRATADA COM TÉCNICA DE RETALHO DUPLO DE MUCOSA ORAL - RELATO DE CASO
}

(Bilateral oronasal fistula in a dog treated with a double oral mucosa flap technique - case report)

Helena Baggio Soares, Rogério Ribas Lange, Dejoara de Angelis Zvoboda, Marcos Vinicius Almeida Moraes

Universidade Federal do Paraná, Curitiba, Paraná, Brasil.

*Correspondência: mvhelenabaggio@gmail.com

RESUMO: Fístula oronasal (FON) é uma comunicação patológica entre as cavidades oral e nasal e ocorrem, em sua maioria, por doença periodontal grave com perda óssea maxilar, mas também podem ocorrer por trauma, lesões iatrogênicas, neoplasias, defeitos congênitos ou extrações dentárias. A FON geralmente é consequência de extração dentária durante o tratamento periodontal, sendo mais frequente em ocasião de exodontia de caninos ou incisivos superiores. Os sinais clínicos são secreção nasal uni ou bilateral e espirros frequentes, anorexia e halitose. $O$ tratamento de escolha é cirúrgico, com a redução da fístula com retalho duplo de mucosa propiciando os melhores resultados. Foi atendido um cão da raça pinscher, de quatro anos, com histórico de esfoliação de canino superior direito (104) após trauma ocorrido há dois meses. Tutor relatou que animal apresentava espirros frequentes desde então. $\mathrm{Na}$ inspeção da cavidade oral, foi observada doença periodontal grau III, ausência do dente 104 e FON nessa região. Foi indicado tratamento periodontal e redução de FON. No primeiro procedimento, foi realizado o tratamento periodontal com exodontias. Paciente retornou em seis dias para avaliação, na qual foi observada cicatrização em locais de extração e presença de FON em regiões de 104 e 204. Tutor foi orientado a realizar escovação dentária diária e retornar em dois meses para reavaliação. Nesta, foi constatada presença de fístula bilateral sem diminuição. Foi então realizada cirurgia para redução de FON de 204. Dois dias antes da cirurgia foram prescritos ao paciente antibiótico (amoxicilina com clavulanato de potássio $18 \mathrm{mg} / \mathrm{kg}$ ) e anti-inflamatório (meloxicam $0,1 \mathrm{mg} / \mathrm{kg}$ ). A técnica cirúrgica iniciou com um primeiro retalho de mucosa a ser feito a partir do palato duro: realizouse uma incisão partindo do bordo cranial da fístula, chegando à linha mediana do palato e outra incisão partindo do bordo caudal da fístula, também chegando à linha mediana do palato, formando um retalho em formato de U. Esse retalho foi divulsionado com elevador de periósteo e sobreposto à fístula e suturado com fio absorvível poliglactina 4-0. O segundo retalho deve sobrepor o local da fístula e o defeito em palato criado pelo primeiro retalho doador e foi preparado realizando duas incisões divergentes em mucosa jugal, paralelas às extremidades cranial e caudal da fístula e liberando-a com tesoura romba. Foi então suturado com pontos simples de modo a cobrir todo o primeiro retalho e o defeito causado pela sua doação em palato. No pósoperatório foi indicado uso de colar elisabetano e alimentação pastosa por 30 dias. A medicação pós-operatória prescrita para o paciente foram os mesmos do pré-operatório, incluindo analgésico. Em nova avaliação, a fístula de 204 havia sido reduzida. Foi marcada nova cirurgia para redução de fístula contralateral dois meses depois. Também foi feito retalho duplo em local de 104 e a técnica cirúrgica utilizada foi a mesma, além das mesmas indicações pré e pós-operatórias. Um mês depois o paciente apresentava cicatrização no local de reparo de fístula oronasal (104) e sua consequente redução. Pacientes de redução de FON devem ser acompanhados com certa regularidade.

Palavras-chave: comunicação patológica; doença periodontal; redução de fístula 